\section{Need for Emergency Epinephrine to Treat Food Allergy Reactions in Schools in the Hortaleza District in Madrid}

Cabrera $\mathrm{M}^{1}$, Ortiz-Menéndez $\mathrm{JC}^{2}$, Garzón B ${ }^{3}$, Barrios L ${ }^{3}$ ${ }^{I}$ Servicio de Alergia, Hospital "Los Madroños, Brunete, Madrid ${ }^{2}$ Departamento Servicios Sanitarios Calidad y Consumo, ImFINE Research Group, Universidad Politécnica de Madrid, Madrid ${ }^{3}$ Unidad de Estadística, Secretaría Adjunta de Informática, Consejo Superior de Investigaciones Cientificas (CSIC), Madrid

J Investig Allergol Clin Immunol 2017; Vol. 27(1): 58-60 doi: $10.18176 /$ jiaci.0114

Key words: Food allergy. Anaphylaxis. Epinephrine autoinjector. School canteens.

Palabras clave: Alergia a alimentos. Anafilaxia. Autoinyector de adrenalina. Comedores escolares.

In Spain, almost 2 million children (1916621 students) eat meals provided by a catering service at 15646 schools every day [1]. The school environment presents significant challenges in terms of managing potentially life-threatening food allergies. Over a 2-year period, schools can expect approximately $18 \%$ of students to have at least 1 foodallergic reaction while at school [2]. A population-based study conducted in Alcorcón, Madrid, found that food-induced anaphylaxis was most common in children aged 0 to 4 years old in both the general population and children seen at an emergency department [3]. During the period 1998 to 2011, the Spanish hospital system recorded a 1.89-fold increase in admissions for anaphylaxis. The increase was particularly evident in patients aged 0 to 14 years old (1.65- to 3.22-fold increase up to 2009 and 4.09- to 12.59-fold increase up to 2011) and in all age groups in the case of food anaphylaxis (2.78-fold increase up to 2009 and 8.74-fold increase up to 2011) [4]. Although there are no specific data on fatalities in school settings, a crude cumulative incidence of 0.9 episodes of anaphylaxis per 1000 emergency episodes (95\% CI, $0.8-1.1)$ and 0.8 episodes per 1000 people $(95 \% \mathrm{CI}, 0.7-0.9)$ has been described [5].

The food allergy guidelines sponsored by the National Institute of Allergy and Infectious Diseases cite a study that revealed that a significant percentage of children with food allergies do not have access to epinephrine at school [6]. Given that most children spend a significant amount of time at school, proper management of food allergies in this setting is critical. In brief, proper prevention and preparedness measures are essential during a child's transition from home to school.
Most experts agree that students with food allergies should have an emergency action plan (AP), similar to those used for students with asthma [7]. In Spain, schools have access to a food allergy AP designed by the AEPNAA (Spanish Association for People with Food and Latex Allergies) (http:// www.aepnaa.org/te-podemos-ayudar/protocolo-de-actuacionante-una-reaccion-alergica-en-la-escuela-aepnaa-47) and endorsed by the Spanish scientific community. It provides specific instructions on how to treat children in the event of exposure or reaction to a food allergen.

We previously described the prevalence of food allergenfree diets in school canteens in the Hortaleza District of Madrid based on clinical reports by specialists [8]. Since 2009, we have been following students diagnosed with food allergies in the schools in this district, and implementing measures related to food safety information, training, and control. One example is a letter sent to all families by the school principals insisting on the importance of drawing up an AP for children with food allergies. In this article, we describe the need for epinephrine auto-injector prescription among children with food-induced allergic reactions at schools in the Hortaleza District during the school year 2013-2014.

The results reported correspond to children at all 86 schools in the Hortaleza District (100\% participation in the survey). A previously administered structured questionnaire on special diets [8], including information about the AP (available online), was completed for the study period. For students without an AP, only the type of allergen-free diet they were on was noted. Other data recorded included sex, age, and type of school. Frequencies were computed in the winter of 2015. The Bonferroni correction was used to account for multiple comparisons. The relationships between food variables and epinephrine prescription were determined by cross-tabulation, with Monte Carlo estimation of exact $P$ values. Bonferroni correction was also used to compare column proportions. These tests were performed in SPSS V23.

Of the 20653 children served meals in the school year analyzed, $1182(5.7 \%)$ were served an allergen-free diet. Of these, $251(21.2 \%)$ had a food allergy AP and 185 (72.1\% of all those with an AP and $15.6 \%$ of those with a reported food allergy) had a prescription for epinephrine use. Nine of the children with an auto-injector were under 3 years old, 60 were between 3 and 5 years old, 104 were aged between 6 and 14 years, and 12 were 15 years or older. These students accounted for $0.8 \%$ of all children served allergen-free diets in the school year studied. The highest proportions of epinephrine use were observed in children with allergies to shellfish (84.2\%), fish (82.1\%), egg $(78.7 \%)$, peanuts $(76.9 \%)$, milk $(76.1 \%)$, and nuts $(76.1 \%)$ (Table). The differences, however, with respect to the population of all children with food allergies were not statistically significant $(P>.05)$. No association was detected between food allergy groups and proportion of epinephrine use. 
Table. Number of Children With Food Allergies and Injectable Epinephrine Device Prescription Based on 251 Students ${ }^{\mathrm{a}}$ With a Food Allergy Action Plan

\begin{tabular}{l|c|c|c|c|c|c|}
\hline & Diagnosis of Food Allergy & No Epinephrine Use & \multicolumn{3}{|c|}{ Epinephrine Use } \\
\hline & No. & No. & $\%$ & No. & $\%$ & \multicolumn{1}{c}{ P Value } \\
\hline Egg & 108 & 23 & $21.3 \%$ & 85 & $78.7 \%$ & .148 \\
Fruits (Rosaceae) & 40 & 15 & $37.5 \%$ & 25 & $62.5 \%$ & .115 \\
Fruits (other than Rosaceae) & 50 & 16 & $32.0 \%$ & 34 & $68.0 \%$ & .198 \\
Nuts & 110 & 28 & $25.5 \%$ & 82 & $74.5 \%$ & .885 \\
Peanuts & 13 & 3 & $23.1 \%$ & 10 & $76.9 \%$ & $>.999$ \\
Fish & 39 & 7 & $17.9 \%$ & 32 & $82.1 \%$ & .238 \\
Shellfish & 19 & 3 & $15.8 \%$ & 16 & $84.2 \%$ & .417 \\
Milk & 46 & 11 & $23.9 \%$ & 35 & $76.1 \%$ & .717 \\
Legumes & 26 & 6 & $23.1 \%$ & 20 & $76.9 \%$ & .817 \\
Vegetables & 19 & 6 & $31.6 \%$ & 13 & $68.4 \%$ & .593 \\
\hline
\end{tabular}

a Some students had more than 1 food allergen-free diet (polysensitized patients).

${ }^{\mathrm{b} B}$ Bonferroni correction was used to compare column proportions.

'Significance level $P<.05$.

There was a low proportion of APs drawn up by allergists in this school population. The proportion of auto-injector prescription (15.6\%) was lower than that described recently by Múgica-García et al. (21.53\%) [9]. According to data from the European Anaphylaxis Registry, food is the most common elicitor of anaphylaxis in children, and the main triggers are hen's egg, cow's milk and nuts [10]. These triggers were also common in our series, but fish and shellfish allergies were the most frequent reasons for epinephrine prescription. The difference could be due to a socioeconomic factor, as previously reported [8], as fish and shellfish allergies were more prevalent in private or grant-aided schools, which are characterized by higher-income families and greater consumption of these foods $(P<.001)$.

The low proportion of children under 3 years old with epinephrine injectors can be explained by the fact that only $5.29 \%$ of the schools surveyed had children in this age group; the most common food allergies in this group are egg and milk (55.67\% and $40.21 \%$, respectively) [8]. Food-induced anaphylaxis is increasing in Madrid and is more common in children aged 0 to 4 years than in other age groups [3]. Particular attention should thus be paid to prevention and care measures in this young population, especially in day care centers. Measures extending beyond those recommended during regular visits to allergists are needed to increase the use of epinephrine auto-injectors.

We will continue to reinforce food allergy notification in our health district. This is the first large urban school district in Spain to develop and implement a food allergy survey, which has helped 185 students and school staff to avoid potential morbidity and mortality due to food allergy. The impact of this initiative during its first year underscores the need to stock epinephrine in schools in our district.

\section{Acknowledgments}

We thank all families and school staff who made this project possible.
Funding

The authors declare that no funding was received for the present study.

Conflicts of Interest

The authors declare that they have no conflicts of interest.

\section{References}

1. Morán Fagúndez LJ, Rivera Torres A. Alimentación en comedores escolares. Nutrición Clínica en Medicina. Nutr Clin Med 2015; IX (3): 204-18.

2. Nowak-Wegrzyn A. Conover-Walker MK. Wood RA. Foodallergic reactions in schools and preschools. Arch Pediatr Adolesc Med. 2001;155(7):790-5.

3. Tejedor Alonso MA, Moro Moro M, Múgica García MV, Esteban Hernández J, Rosado Ingelmo A, Vila Albelda C, Gomez Traseira C, Cardenas Contreras R, Sanz Sacristán J, Hernández Merino A. Incidence of anaphylaxis in the city of Alcorcon (Spain): a population-based study. Clin Exp Allergy. 2012 Apr;42(4):578-89.

4. Tejedor-Alonso MA, Moro-Moro M, Mosquera González M, Rodriguez-Alvarez M, Pérez Fernández E, Latasa Zamalloa P, Farias Aquino E, Gil Prieto R, Gil de Miguel A. Increased incidence of admissions for anaphylaxis in Spain 1998-2011. Allergy. $2015 \mathrm{Jul} ; 70(7): 880-3$.

5. Moro Moro M, Tejedor Alonso MA, Esteban Hernández J, Múgica García MV, Rosado Ingelmo A, Vila Albelda C. Incidence of Anaphylaxis and Subtypes of Anaphylaxis in a General Hospital Emergency Department I Investig Allergol Clin Immunol. 2011;Vol. 21(2):142-9.

6. Ben-Shoshan $M$, Kagan $R$, Primeau $M N$, Alizadehfar $R$, Verreault N, Yu JW, Nicolas N, Joseph L, Turnbull E, Dufresne C, St Pierre Y, Clarke A. Availability of the epinephrine autoinjector at school in children with peanut allergy. Ann Allergy Asthma Immunol. 2008 Jun;100(6):570-5. 
7. Young MC. Muñoz-Furlong A. Sicherer SH. Management of food allergies in schools: a perspective for allergists. J Allergy Clin Immunol. 2009;124(2):175-182.

8. Cabrera M. Ortiz-Menéndez JC. López-Gay D. Prevalence of food allergen-free diets in school canteens in Hortaleza district. Madrid. Pediatr Allergy Immunol. 2014 Nov;25(7):719-21.

9. Múgica-García MV, Tejedor-Alonso MA, Moro-Moro M, Esteban-Hernández J, Rojas-Perez-Ezquerra PE, Vila-Albelda C, Rosado-Ingelmo A. Self-Management of Anaphylaxis Is Not Optimal. J Investig Allergol Clin Immunol. 2015;25(6):408-15.

10. Grabenhenrich LB. Dölle S. Moneret-Vautrin A. Köhli A. Lange L. Spindler T. Ruëff F. Nemat K. Maris. Roumpedaki E. Scherer K11. Ott H. Reese T. Mustakov T. Lang R. Fernandez-Rivas M. Kowalski ML. Bilò MB. Hourihane JO. Papadopoulos NG. Beyer K. Muraro A. Worm M. Anaphylaxis in children and adolescents: The European Anaphylaxis Registry. J Allergy Clin Immunol. 2016;137(4):1128-37.

I Manuscript received May 31, 2016; accepted for publication, September 29, 2016.

\section{Occupational Asthma to Detergent Protease Associated With a Late-Phase Neutrophilic Cutaneous Response}

Poussel $\mathrm{M}^{1,2}$, Penven $\mathrm{E}^{3,4}$, Essari $\mathrm{LA}^{1,5}$, Chabot $\mathrm{F}^{4,5}$, Barbaud $\mathrm{A}^{4,6}$, Paris $\mathrm{C}^{3,4}$

${ }^{1}$ Department of Pulmonary Function Testing and Exercise Physiology, CHRU Nancy, Nancy, France

${ }^{2}$ EA 3450 DevAH - Development, Adaptation and Disadvantage, Cardiorespiratory Regulations and Motor Control, Université de Lorraine, Vandoeuvre-lès-Nancy, France

${ }^{3}$ Occupational Diseases Department, Bâtiment Philippe Canton, CHRU Nancy, Vandoeuvre-lès-Nancy, France

${ }^{4}$ EA-7298 INGRES, Université de Lorraine, Vandoeuvre-lèsNancy, France

${ }^{5}$ Pulmonology Department, CHRU Nancy, Nancy, France

${ }^{6}$ Department of Dermatology and Allergy, CHRU Nancy, Vandoeuvre-lès-Nancy, France

J Investig Allergol Clin Immunol 2017; Vol. 27(1): 60-62 doi: $10.18176 /$ jiaci.0115

Key words: Occupational asthma. Specific inhalation challenge. Protease. Neutrophilic response.

Palabras clave: Asma ocupacional. Provocación específica por inhalación. Proteasa. Respuesta neutrofílica.

Proteolytic enzymes are widely used in laundry detergent products. The high-molecular-weight (HMW) antigens present in these enzymes are known to induce occupational asthma (OA) via a specific IgE response with a clear exposureresponse relationship $[1,2]$. Aiming to reduce levels of exposure among employees, most modern detergent factories now only use encapsulated enzymes. However, despite the prevention strategies established, enzyme-induced OA is still reported [3]. We describe a case of OA to protease associated with a late-phase neutrophilic cutaneous response and discuss other possible mechanisms involved in such uncommon cases of IgE-induced OA.

We investigated a 47-year-old woman (ex-smoker with a 15 pack-year history) who had been working for more than 12 years as a process operator in a modern dishwashing tablet factory. This previously healthy patient (with no personal or family history of allergy) had been employed since 2003 and was occasionally exposed to detergent enzymes (principally amylase and protease) incorporated into the tablets produced. Although the manufacturing process used encapsulated enzymes, our patient was briefly but frequently exposed to crushed capsules during daily maintenance procedures (once or twice a day with a cumulative exposure time of 3060 minutes). Since 2005 she had progressively complained of respiratory symptoms (cough, shortness of breath, and wheezing), the occurrence of which was clearly modulated by work-related exposure, as symptoms declined during nonworking periods. Initial investigations conducted while 
the patient was still working did not show baseline airway obstruction (forced expiratory volume in the first second $\left[\mathrm{FEV}_{1}\right], 2.46 \mathrm{~L} ; 96 \%$ of predicted value; $\mathrm{FEV}_{1} /$ forced vital capacity, 74\%), but did show an increased fraction of exhaled nitric oxide (FeNO), at $322.95 \mathrm{ppb}$. A methacholine challenge showed nonspecific bronchial hyperresponsiveness with a $20 \%$ decrease in $\mathrm{FEV}_{1}$ for a cumulative dose of $1800 \mu \mathrm{g}$ of $1 \%$ methacholine (roughly $4 \mathrm{mg} / \mathrm{mL}$ ) associated with compatible respiratory symptoms (cough and wheezing). Serial monitoring of peak expiratory flow at and away from work over a 6-week period allowed the calculation of an Oasys score of 2.1 (normal, <2.5). The blood count was normal and specific IgE (ImmunoCAP Specific IgE) for the suspected protease was $5.1 \mathrm{kU} / \mathrm{L}$ (reference value, $<0.35 \mathrm{kU} / \mathrm{L}$ ). After a 7 -week period of avoidance of exposure to detergent enzymes (nonworking period), during which the symptoms regressed completely, further investigations were performed. A specific inhalation challenge (SIC) to crushed encapsulated protease (Excellenz P1000) was performed according to recent guidelines [4] with a $20 \%$ concentration powder diluted in lactose. The duration of exposure (dust dipping method) was gradually increased (10 seconds, 1 minute, 5 minutes, 10 minutes, and 15 minutes). During the fifth step of exposure, ie, at 15 minutes, the SIC showed a positive reaction with chest tightness, dyspnea, and wheezing, associated with a $23 \%$ fall in $\mathrm{FEV}_{1}$ compared with baseline. Reversibility was obtained within 15 minutes of the end of

Table. Results of Specific Inhalation Challenge to Crushed Encapsulated Protease (Excellenz P1000)

\begin{tabular}{lcccc}
\hline & FEV $_{1}(\mathrm{~L})$ & $\begin{array}{c}\mathrm{FEV}_{1} \\
(\% \text { of pred })\end{array}$ & $\begin{array}{c}\mathrm{FEV}_{1} / \\
\mathrm{FVC}\end{array}$ & $\begin{array}{c}\mathrm{FeNO} \\
(\mathrm{ppb})\end{array}$ \\
\hline Baseline & 2.40 & 94 & 0.72 & 100.65 \\
$10 \mathrm{~s}$ & 2.43 & 95 & 0.73 & - \\
$1 \mathrm{~min}$ & 2.43 & 95 & 0.75 & - \\
5 min & 2.40 & 94 & 0.72 & - \\
10 min & 2.29 & 90 & 0.72 & - \\
15 min & 1.85 & 72 & 0.66 & - \\
Post $\beta_{2}$ & 2.42 & 95 & 0.74 & - \\
Post 30 min & 2.54 & 100 & 0.76 & - \\
Post $60 \mathrm{~min}$ & 2.45 & 96 & 0.74 & - \\
Post $2 \mathrm{~h}$ & 2.43 & 95 & 0.74 & - \\
Post $3 \mathrm{~h}$ & 2.43 & 95 & 0.74 & - \\
Post $4 \mathrm{~h}$ & 2.27 & 89 & 0.72 & - \\
Post $5 \mathrm{~h}$ & 2.12 & 83 & 0.71 & - \\
Post $6 \mathrm{~h}$ & 2.02 & 79 & 0.68 & - \\
Post $\beta_{2}$ & 2.54 & 100 & 0.77 & - \\
Post $12 \mathrm{~h}$ & 2.40 & 94 & 0.73 & - \\
Post $24 \mathrm{~h}$ & 2.22 & 87 & 0.72 & 232.3 \\
\hline
\end{tabular}

Abbreviations: $\beta_{2}$, short-acting $\beta_{2}$-agonist (salbutamol, $400 \mu \mathrm{g}$ ); $\mathrm{FeNO}$, fractional exhaled nitric oxide; $\mathrm{FEV}_{1}$, forced expiratory volume in the first second; FVC, forced vital capacity; pred, predicted. the SIC with a $\beta_{2}$-agonist, but delayed respiratory symptoms and bronchoconstriction emerged 6 hours later $(16 \%$ fall in $\mathrm{FEV}_{1}$ compared with baseline) and during the night (15 hours after the SIC), prompting $\beta_{2}$-agonist aerosol therapy. FeNO and sputum eosinophil counts evaluated at baseline and 24 hours after the SIC showed an increase in FeNO from 100.65 to $232.3 \mathrm{ppb}$, and an increase in eosinophil count from $1 \%$ to $65 \%$. A skin prick test (SPT) with a $1 \%$ solution of crushed encapsulated protease was positive, with a wheal diameter of $10 \mathrm{~mm}$ (vs $5 \mathrm{~mm}$ for the histamine control and $0 \mathrm{~mm}$ for the saline control). Control prick tests with crushed encapsulated protease were negative in 3 volunteers who had never been exposed. The patient presented a late cutaneous reaction (at 24 hours) characterized by erythema and edema on the forearm where the SPT had been performed. Histologic examination of the cutaneous biopsy specimen showed neutrophilic urticaria with dermal edema associated with a sparse perivascular and interstitial infiltrate mostly composed of neutrophils. A diagnosis of OA due to detergent protease was made.

Evidence now suggests that patients with OA should be differentiated according to the agent suspected to be involved (ie, HMW vs LMW) [5-7]. HMW agents have been shown to cause OA through an IgE-dependent mechanism [8], and the characteristics of the airway inflammation (increased FeNO and eosinophil count following the SIC $[5,6]$ ) are largely related to a type 2 helper $\mathrm{T}$ cell $\left(\mathrm{T}_{\mathrm{H}} 2\right)$ activation profile. In our case, such an IgE-mediated mechanism is supported by the presence of specific IgE to the suspected protease, the immediate positive reaction to the SPT and SIC, and the increase in FeNO and sputum eosinophil counts after the SIC. However, bronchial neutrophilic inflammation has also been reported in some OA patients exposed to HMW agents [6]. In our observation, the 24-hour delay in the SPT reaction to protease combined with the neutrophilic appearance of the reaction in the skin biopsy allowed us to further hypothesize on the possible mechanisms involved in this particular case of HMW-induced OA. Indeed, even if the precise underlying mechanisms of bronchial neutrophilic inflammation remain unknown, airway exposure to allergens in sensitized individuals may induce a $\mathrm{T}_{\mathrm{H}} 17$ response with the release of IL-17. This $\mathrm{T}_{\mathrm{H}} 17$-associated immune response (involving IL-1 at the origin of the response) seems to play a key role in the development of a neutrophilic phenotype asthma (characterized by greater airflow obstruction, severity, and steroid resistance) by inducing allergic airway inflammation via the expression of various proinflammatory mediators [9]. Neutrophilic urticaria, in turn, is a rare variant of urticaria that has been reported to be frequently associated with extracutaneous inflammation, supporting a role for IL-1 in driving a particular inflammatory reaction [10]. The association of IgE-induced OA and a late-phase neutrophilic cutaneous reaction in the case presented here could therefore further support the possible implication of a neutrophildriven inflammation component that could satisfy the proposed terminology of neutrophilic urticaria with systemic inflammation (NUSI) [9], and that may be also associated with the work environment. However, these findings may be also the result of a direct inflammation mechanism induced 
by the protease itself at the skin level, as we did not observe any bronchial neutrophilic reaction in sputum at 24 hours.

To our knowledge, this is the first report of OA to detergent protease documented through current guidelines [4,7] associated with a late-phase neutrophilic cutaneous reaction, suggesting the potential contribution of neutrophilic inflammation in addition to the known IgE-dependent mechanisms. Of course our hypothesis is based on this single case (representing per se a limitation), but further studies may be helpful to evaluate with greater precision this possible new OA phenotype.

\section{Funding}

The authors declare that no funding was received for the present study.

\section{Conflicts of Interest}

The authors declare that they have no conflicts of interest.

\section{References}

1. Cullinan $P$, Harris JM, Newman Taylor AJ, Hole AM, Jones $M$, Barnes $F$, Jolliffe $G$. An outbreak of asthma in a modern detergent factory. Lancet. 2000;356:1899-2000.

2. Brant A, Upchurch S, van Tongeren M, Zekveld C, Helm J, Barnes F, Newman Taylor AJ, Cullinan P. Detergent protease exposure and respiratory disease: case-referent analysis of a retrospective cohort. Occup Environ Med. 2009;66:754-8.

3. Lipinska-Ojrzanowska A, Swierczynska-Machura D, Tymoszuk D, Nowakowska-Swirta E, Walusiak-Skorupa J. Occupational asthma in female factory worker resulting from exposure to savinase in dishwashing tablets-a case study. J Occup Health. 2013:55:318-21.

4. Vandenplas $O$, Suojalehto $H$, Aasen TB, Baur $X$, Burge PS, de Blay F, Fishwick D, Hoyle J, Maestrelli P, Munoz X, Moscato G, Sastre J, Sigsgaard T, Suuronen K, Walusiak-Skorupa J, Cullinan P. Specific inhalation challenge in the diagnosis of occupational asthma: consensus statement. ERS Task Force Report. Eur Respir J. 2014;43:1573-87.

5. Lemière C, Nguyen S, Sava F, D'Alpaos V, Huaux F, Vandenplas O. Occupational asthma phenotypes identified by increased fractional exhaled nitric oxide after exposure to causal agents. J Allergy Clin Immunol. 2014;134:1063-7.

6. Sanchez-Vidaurre S, Cruz MJ, Gomez-Olles S, Munoz X. Sputum inflammatory profile before and after specific inhalation challenge in individuals with suspected occupational asthma. PLoS One. 2013;8(11):e78304.

7. Munoz X, Cruz MJ, Bustamante V, Lopez-Campos JL, Barreiro E. Work-related asthma: diagnosis and prognosis of immunological occupational asthma and workexacerbated asthma. J Investig Allergol Clin Immunol. 2014;24:396-405.

8. Tarlo SM, Lemière C. Occupational asthma. N Engl J Med. 2014;370:640-9.

9. Romagnani S, Maggi E, Liotta F, Cosmi L, Annunziato F. Properties and origin of human Th17 cells. Mol Immunol. 2009;47:3-7.
10. Belani H, Gensler L, Bajpai U, Meinhardt E, Graf J, Pincus L, Leslie KS. Neutrophilic urticarial with systemic inflammation: a case series. JAMA Dermatol. 2013;149:453-8.

Manuscript received July 13, 2016; accepted for publication, September 30, 2016.

Mathias Poussel Service des Examens de la Fonction Respiratoire et de

I'Aptitude à l'Exercice CHRU Nancy

Nancy, F-54000, France E-mail: m.poussel@chru-nancy.fr 


\section{Psoriatic Erythroderma Caused by Terbinafine: A Possible Pathogenetic Role for IL-23}

Oda T, Sawada Y, Yamaguchi T, Ohmori S, Omoto D, Haruyama S, Yoshioka M, Okada E, Nakamura M

Department of Dermatology, University of Occupational and Environmental Health, Kitakyūshū, Japan

J Investig Allergol Clin Immunol 2017; Vol. 27(1): 63-64 doi: $10.18176 /$ jiaci.0116

Key words: Drug eruption. Psoriatic erythroderma. Terbinafine. IL-23.

Palabras clave: Erupción medicamentosa. Eritrodermia psoriásica. Terbinafina. IL 23.

Terbinafine is an active allylamine derivative that inhibits squalene epoxidase in ergosterol biosynthesis, resulting in the accumulation of intracellular squalene, which is toxic to fungal cells [1]. On occasions, however, terbinafine can also cause several types of cutaneous adverse reactions. Herein, we report a case of psoriatic erythroderma caused by terbinafine and further analyze a possible pathogenetic role for IL-23 in psoriasiform drug eruption.

An 84-year-old woman had noticed scaly erythematous plaques on the trunk and extremities and subsequently developed generalized scaly erythema. She was referred to our department for evaluation. She had taken terbinafine to treat tinea unguium for 1 month. There was no personal or family history of psoriasis. Physical examination revealed erythroderma with a silvery-white scaly erythema on the scalp (Figure A) and a generalized scaly erythema without pustules on the trunk (Figure B) and extremities (Figure C), indicating erythroderma. She had no fever. Laboratory tests revealed an elevation of C-reactive protein at $2.32 \mathrm{mg} / \mathrm{dL}$ (normal, $<0.2 \mathrm{mg} / \mathrm{dL}$ ). Examination of a skin biopsy specimen taken from a scaly erythema showed parakeratosis and acanthosis accompanied by a less granular layer (Figure D). Additional findings included neutrophil and eosinophil infiltration in the upper and middle dermis and dyskeratotic keratinocytes in the epidermis with a neutrophil microabscess in a horny layer.
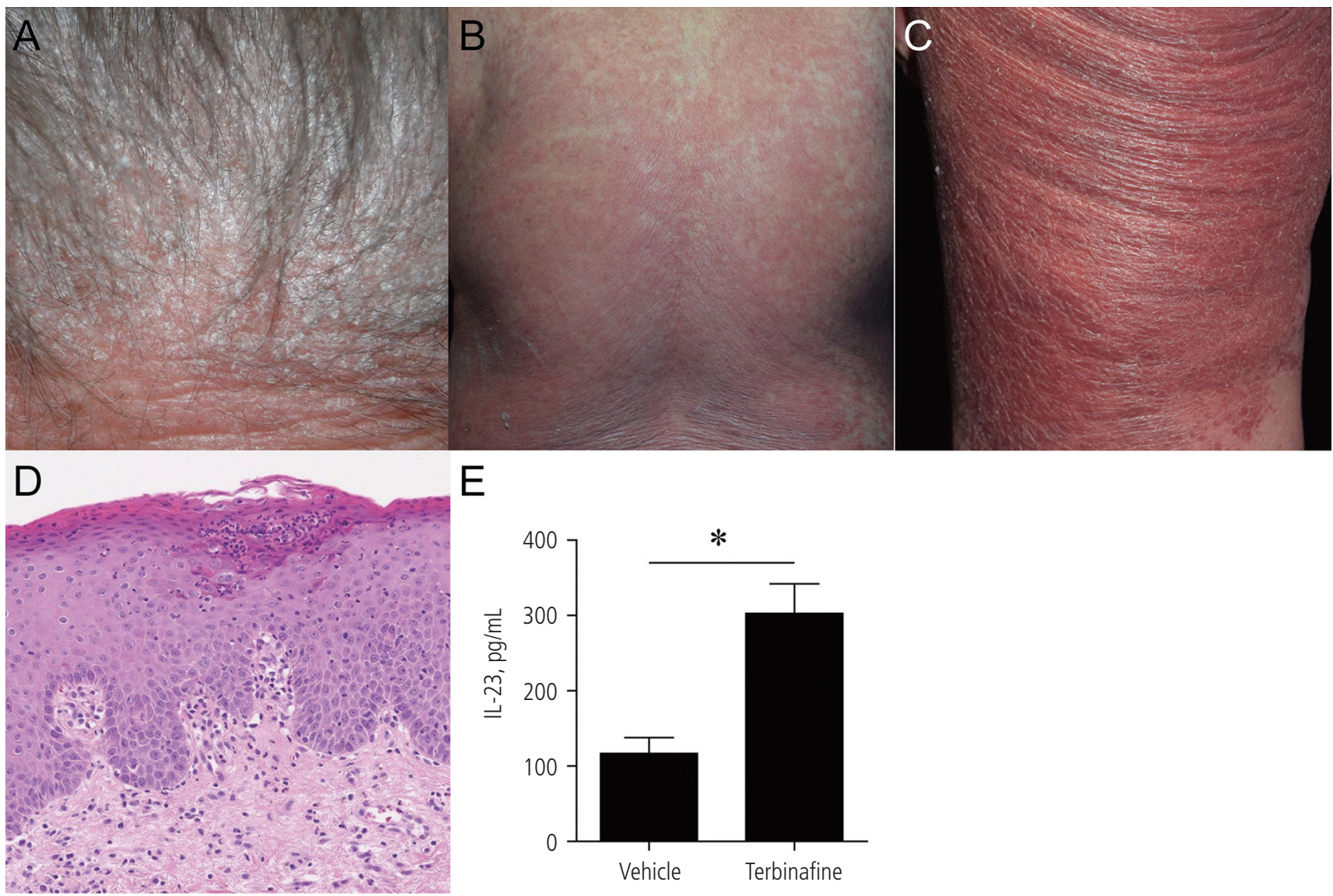

$E$

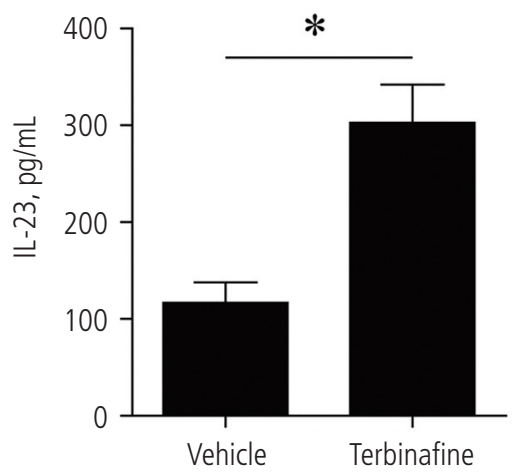

Figure. Clinical manifestations and laboratory findings. A-C, Clinical manifestations consisting of annular scaly erythematous plaques on the scalp (A), trunk (B), and left thigh (C). D, Histopathology of the skin showing parakeratotic hyperkeratosis with acanthosis and localized thinning of the granular layer and infiltrated neutrophils in the epidermis and dermis. E, IL-23 concentrations. IL-23 concentrations were measured by ELISA in the culture supernatant of a lymphocyte stimulation test in which the patient's peripheral blood mononuclear cells ( $3 \times 105$ cells) were stimulated with terbinafine for 72 hours. Results are presented as mean \pm SEM. The $P$ value was calculated using the $t$ test. ${ }^{\star} P<.05$. 
The clinical course and laboratory findings suggested psoriatic erythroderma possibly due to a drug.

To investigate the cause, we performed a lymphocyte stimulation test (LST) with terbinafine as previously described $[2,3] .{ }^{3} \mathrm{H}$-thymidine incorporation was significantly increased by the addition of $2.2 \times 10-6 \mathrm{M}$ terbinafine (corresponding to $\mathrm{C}_{\max }$ ) to the peripheral lymphocyte culture, with a stimulation index of 2.8 . The patient was treated with oral methylprednisolone $20 \mathrm{mg} / \mathrm{d}$ and topical betamethasone butyrate propionate ointment with discontinuation of terbinafine. The eruption improved remarkably within 2 weeks, leaving only residual pigmentation. A patch test with $10 \%$ terbinafine was positive after treatment. Based on the clinical course and laboratory findings, the rash was diagnosed as psoriatic erythroderma possibly due to terbinafine.

T helper type $17\left(\mathrm{~T}_{\mathrm{H}} 17\right)$ cells appear to play an important role in the pathogenesis of psoriasiform drug eruption [4], and IL-23 from dendritic cells has an important role in activating IL-17 production from $\mathrm{T}_{\mathrm{H}} 17$ cells [5]. Furthermore, an IL-17 antagonist was recently reported to improve psoriatic erythroderma [6]. Therefore, it has been speculated that the IL-23/IL-17 axis might also contribute to the pathogenesis of drug-induced psoriatic erythroderma. Furthermore, IL-23 from dendritic cells has been found to play an important role in an imiquimod-induced psoriasis mouse model [7]. To clarify the role of IL-23 in this case of psoriatic erythroderma, we used ELISA to measure the level of this cytokine in culture supernatant following LST, and found that it was significantly increased by terbinafine stimulation (Figure E). This finding indicates that IL-23 might be involved in the pathogenesis of psoriatic erythroderma. Because of the limited number of cases, further analysis is necessary to clarify the role of IL-23 in the pathogenesis of psoriatic erythroderma.

\section{Funding}

The authors declare that no funding was received for the present study.

\section{Conflicts of Interest}

The authors declare that they have no conflicts of interest.

\section{References}

1. Ryder NS. Terbinafine: mode of action and properties of the squalene epoxidase inhibition. Br J Dermatol. 1992;126(39):2-7.

2. Inoue $A$, Sawada $Y$, Ohmori $S$, Omoto D, Haruyama S, Yoshioka M, Nishio D, Nakamura M. CD30-positive cutaneous pseudolymphoma caused by tocilizumab in a patient with rheumatoid arthritis: case report and literature review. Acta Derm Venereol. 2016;96(4):570-1.

3. Sakuragi $Y$, Sawada $Y$, Hara $Y$, Ohmori S, Omoto D, Haruyama S, Yoshioka M, Nishio D, Nakamura M. Acute Generalized Exanthematous Pustulosis Caused by Faropenem: A Possible Pathogenetic Role for Interleukin-23. Acta Derm Venereol. 2016;96(2):265-6.

4. Teraki Y, Tanaka S, Hitomi K, Izaki S. A case of generalized psoriasiform and pustular eruption induced by infliximab: evidence for skin-homing Th17 in the pathogenesis. $\mathrm{Br} \mathrm{J}$ Dermatol. 2010;163(6):1347-51.

5. Iwakura $Y$, Ishigame $H$. The IL-23/IL-17 axis in inflammation. J Clin Invest. 2006;116(5):1218-22.

6. Yamasaki K, Nakagawa H, Kubo Y, Ootaki K. Efficacy and safety of brodalumab in patients with generalized pustular psoriasis and psoriatic erythroderma: results from a 52-week, open-label study. Br J Dermatol. doi: 10.1111/bjd.14702.

7. Yoshiki R, Kabashima K, Honda T, Nakamizo S, Sawada Y, Sugita K, Yoshioka H, Ohmori S, Malissen B, Tokura Y, Nakamura M. IL-23 from Langerhans cells is required for the development of imiquimod-induced psoriasis-like dermatitis by induction of IL-17A-producing gammadelta T cells. J Invest Dermatol. 2014;134(7):1912-21.

Manuscript received July 27, 2016; accepted for publication, September 30, 2016.

Yu Sawada

Department of Dermatology University of Occupational and Environmental Health. 1-1, Iseigaoka, Yahatanishi-ku Kitakyushu 807-8555, Japan E-mail: long-ago@med.uoeh-u.ac.jp 


\section{The Effects of Prolonged Infusion on Reducing Oxaliplatin Hypersensitivity Reactions}

\author{
Zhang X, Zhao Y, Zheng Y, Dong Y \\ Nursing department, Peking Union Medical College Hospital, \\ Beijing, P. R. China
}

J Investig Allergol Clin Immunol 2017; Vol. 27(1): 65-66 doi: 10.18176/jiaci.0119

Key words: Gastrointestinal malignancies. Oxaliplatin. Oxaliplatin hypersensitivity reaction (OHSR). Prolonged infusion. Standard infusion.

Palabras clave: Tumores gastrointestinales malignos. Oxaliplatino. Reacción de hipersensibilidad a oxaliplatino. Infusión prolongada. Infusión estándar.

Oxaliplatin, as one of the major cytoxic agents, is used extensively to treat colorectal cancer and other gastrointestinal malignancies [1]. Its increasing use has led to a growing number of reports of oxaliplatin hypersensitivity reactions (OHSRs), and some authors have described rates as high as $24.2 \%$ [2]. Hypersensitivity reactions do not only affect treatment, but also increase the cost of hospitalization and can even be life-threatening in the case of severe reactions [3]. Several methods are currently used to prevent OHSRs, such as desensitization, alteration of infusion time, skin testing, and premedication. Some of these methods, however, are considered to be of debatable value or excessively complex. The aim of this study was to evaluate whether a prolonged oxaliplatin infusion schedule might be more effective in reducing OHSRs than standard infusion in a cohort of patients with gastrointestinal malignancies.

We retrospectively reviewed 775 patients with gastrointestinal malignancy patients who received retreatment with oxaliplatin at our hospital from December 2009 to January 2016. The patients were divided into 2 groups: group 1, consisting of 597 patients, treated with the standard oxaliplatin infusion schedule, and group 2, consisting of 178 patients, treated with a prolonged schedule. The prolonged schedule included 2 steps. In step 1, one-fifth of the total dose of oxaliplatin was added to $500 \mathrm{~mL}$ of $5 \%$ glucose and intravenously administered at a uniform drip speed for 1 hour. In step 2, the remaining volume (four-fifths of the total dose) was added to $500 \mathrm{~mL}$ of $5 \%$ glucose and again administered intravenously at a uniform speed for 6 hours. Infusion was stopped after step 1 in the event of an OHSR. In the standard schedule, oxaliplatin was given as a 2-hour intravenous infusion in $500 \mathrm{~mL}$ at a rate of about 60 drips per minute. The National Cancer Institute Common Toxicity Criteria for Adverse Events version 3.0 was used to grade OHSRs. Patients were identified as having an OHSR if they experienced at least 1 of the following symptoms after receiving oxaliplatin: a skin reaction (rash or erythema), bronchospasm, laryngospasm, hypotension or anaphylaxis [4]. The OHSR grading system is as follows: grade 1, transient flushing or rash and drug fever $<38^{\circ} \mathrm{C}$; grade 2 , rash, flushing, urticaria, dyspnea, drug fever $\geq 38^{\circ} \mathrm{C}$; grade 3 , symptomatic bronchospasm, with or without urticaria, indication for parenteral medication, allergy-related edema/angioedema, hypotension; and grade 4, anaphylaxis [1].

Eighty-seven patients were identified as having had an OHSR in this study. The patients with prolonged infusion had a lower risk of OHSRs, as the incidence was much lower than in the standard infusion group $(3.4 \%$ vs $13.6 \%, P<.01$; Table). The difference retained statistical significance $(P<.05)$ in 4 groups of patients: patients treated with oxaliplatin for the first time, patients treated with more than 6 cycles, patients with a history of drug allergy, and patients previously exposed to platinum (Table). Patients in the prolonged infusion group had relatively mild clinical features (mainly mild rash) that resolved quickly. Common systemic symptoms were fever, rash, and pruritus. The clinical significance of our findings is that the prolonged infusion schedule is probably useful for reducing OHSRs in patients with gastrointestinal cancer.

Patient desensitization, modifications to infusion time, skin tests, and premedication are common methods used to prevent OHSRs in clinical practice. Desensitization protocols have proven beneficial, but are relatively complex, timeconsuming, and labor-intensive [2]. Skin testing can help to identify patients at risk for HSRs but it cannot accurately predict the severity of the reactions or reduce their incidence. Premedication (with dexamethasone) seems to be a good choice and is commonly used to reduce OHSRs [5], but some experts think that lower doses of dexamethasone are probably associated with OHSRs [6]. Therefore, compared with the

Table. Comparison of Oxaliplatin Hypersensitivity Reaction Rates with Prolonged and Standard Infusion Schedules

\begin{tabular}{lccc}
\hline Variables & $\begin{array}{c}\text { Prolonged Infusion } \\
(\%, \text { No. of Reactions/No. of Patients })\end{array}$ & $\begin{array}{c}\text { Standard Infusion } \\
(\%, \text { No. of Reactions/No. of Patients) }\end{array}$ & $<$ \\
\hline Total & $3.4,6 / 178$ & $13.6,81 / 597$ & $<.01$ \\
First-time treatment & $1.0,1 / 98$ & $10.1,20 / 198$ & $<.05$ \\
$>6$ cycles & $3.4,2 / 59$ & $14.3,26 / 182$ & $<.05$ \\
History of drug allergy & $7.2,5 / 69$ & $20.0,32 / 160$ & $<.05$ \\
Prior exposure to platinum & $3.6,1 / 28$ & $20.3,15 / 74$ & $<.05$ \\
\hline
\end{tabular}


above methods, the prolonged infusion protocol is probably the simplest and easiest method for reducing OHSRs. This protocol may also reduce the rate of HSRs to carboplatin. O'Cearbhaill et al [7] reported a significantly lower incidence of carboplatin HSRs with a prolonged infusion protocol compared with a standard 30-minute infusion schedule $(3 \%$ vs $21 \%, P<.01$ ) by univariate analysis.

One limitation of our study is that we did not contemplate certain management strategies or novel diagnostic tools including skin tests and IgE for oxaliplatin-based therapy. Our observations should be further investigated and validated in larger clinical studies.

Many systemic OHSR-related symptoms including fever, rash, pruritus, and other moderate to severe allergic symptoms consisting of abdominal cramping, flushing, wheeze, diarrhea, and shock have been reported for the standard oxaliplatin infusion protocol [8]. In this study, OHSRs in patients treated with standard infusion were also relatively severe (13 grade 1 reactions, 62 grade 2 reactions, 5 grade 3 reactions, and 1 grade 4 reaction). By contrast, of the 6 patients who developed an OHSR with the prolonged protocol, 2 had a grade 1 reaction and 4 had a grade 2 reaction, and the symptoms resolved quickly. This observation of less severe reactions with the prolonged scheduled is supported by a previous study [9] and can probably be explained by the decreased toxicity associated with the longer infusion time.

In conclusion, prolonged infusion is a feasible approach for reducing the incidence or severity of OHSRs during the treatment of gastrointestinal malignancies.

\section{Funding}

The authors declare that no funding was received for the present study.

\section{Conflicts of Interest}

The authors declare that they have no conflicts of interest.

\section{References}

1. Yanai T, Satoru I. Successful rechallenge for oxaliplatin hypersensitivity reactions in patients with metastatic colorectal cancer. Anticancer Res. 2012;vol. 32 no. 12. 55216.

2. Syrigou El, Karapanagiotou EM, Alamara CV, Boura PG, Saif MW, Syrigos KN. Hypersensitivity reactions to oxaliplatin: A retrospective study and the development of a desensitization protocol. Clin Colorectal Cancer. 2009;8:106-9.

3. Viale PH. Management of hypersensitivity reactions: A nursing perspective. Oncology (Williston Park, N.Y.). 2009;23:26.

4. Polyzos A, Tsavaris N, Gogas H, Souglakos J, Vambakas L, Vardakas N, Polyzos K, Tsigris C, Mantas D, Papachristodoulou A, Nikiteas N, Karavokyros JG, Felekouras E, Griniatsos J, Giannopoulos A, Kouraklis G. Clinical features of hypersensitivity reactions to oxaliplatin: A 10-year experience. Oncology-Basel. 2009;76:36-41.

5. Lee S, Kang H, Song W, Lee K, Han S, Cho SH. Overcoming oxaliplatin hypersensitivity: Different strategies are needed according to the severity and previous exposure. Cancer Chemoth Pharm. 2014;73:1021-9.

6. Kim $M$, Kang $S$, Lee $S$, Yang $M$, Kim $M$, Song $W$, Kim $S$, Kim Y, Lee K, Cho S, Min K, Lee J, Kim J, Chang Y. Hypersensitivity reactions to oxaliplatin: Clinical features and risk factors in Koreans. Asian Pac J Cancer Prev. 2012;13:1209-15.

7. O'Cearbhaill R, Zhou Q, lasonos A, Hensley ML, Tew WP, Aghajanian C, Spriggs DR, Lichtman SM, Sabbatini PJ. The prophylactic conversion to an extended infusion schedule and use of premedication to prevent hypersensitivity reactions in ovarian cancer patients during carboplatin retreatment. Gynecol Oncol. 2010;116:326-31.

8. Lee C, Gianos M, Klaustermeyer WB. Diagnosis and management of hypersensitivity reactions related to common cancer chemotherapy agents. Ann Allergy Asthma Immunol. 2009;102:179-87.

9. Maindrault-Goebel F, de Gramont A, Louvet C, Andre T, Carola E, Mabro M, Artru P, Gilles V, Lotz JP, Izrael V, Krulik M. Highdose intensity oxaliplatin added to the simplified bimonthly leucovorin and 5-fluorouracil regimen as second-line therapy for metastatic colorectal cancer (FOLFOX 7). Eur J Cancer. 2001;37:1000-5.

Manuscript received August 17, 2016; accepted for publication, October 24, 2016.

Yanwei zhao

Nursing department Peking Union Medical College Hospital 1 Shuai Fu Yuan, Dongcheng District Beijing 100730, P. R. China E-mail: zhaoyanweipumch@163.com 


\section{Asthma Due to Swiss Chard: Identification of a New Allergen}

Jara-Gutiérrez $\mathrm{P}^{1}$, Zafra $\mathrm{MP}^{2}$, Sanz V², Del Pozo V², Fernandez-Nieto $\mathrm{M}^{1}$

${ }^{1}$ Allergy Department Fundación Jiménez Díaz, Madrid, Spain ${ }^{2}$ Department of Immunology, IIS-Fundación Jiménez Díaz, Madrid, Spain

J Investig Allergol Clin Immunol 2017; Vol. 27(1): 67-68 doi: $10.18176 /$ jiaci.0120

Key words: Food allergy. Swiss chard allergy. Asthma food allergy. Allergen identification.

Palabras clave: Alergia alimentaria. Alergia a acelga. Asma por alergia a alimentos. Identificación de alérgenos.

Food allergy is common, especially when a particular allergen is ingested, although allergic symptoms can sometimes be produced by skin contact or inhalation of volatile food antigens. Exposure to these allergens is often seen in occupational environments but it is also relatively common in nonoccupational settings, such as the home. In the majority of patients, food-particle inhalation induces respiratory symptoms, which can be nasal (rhinorrhea, sneezing, nasal congestion) or ocular (tearing, redness, irritation), or affect the lower respiratory tract (cough, wheezing). Patients can also develop skin manifestations or, though rarely, anaphylaxis $[1,2]$.

Swiss chard (Beta vulgaris L. cicla) is a widely consumed vegetable in Spain. It belongs to the Chenopodiaceae family, along with spinach, beets, chenopod, and salsola.

Here, we report the case of a 54-year-old woman who developed cough, conjunctival hyperemia, chemosis, and eyelid angioedema (identified by a physician) a few minutes after handling Swiss chard. There was no hemodynamic compromise and the symptoms resolved after systemic corticosteroid administration.

The patient did not experience any symptoms on handling beet or spinach or on ingesting these foods or boiled Swiss chard.

We performed a skin prick test with a series of common aeroallergens, Swiss chard, lipid transfer protein, and profilin (ALK-Abello) and prick-prick tests with raw Swiss chard, spinach, sugar beet, lettuce, and onion. Positive results were obtained for grass pollen, olive, Cupressus, Plantago, Artemisia, Swiss chard, and profilin

Determination of specific IgE (Phadia ImmunoCAP) to beet and spinach showed a positive result for beet $(0.84 \mathrm{kU} / \mathrm{L})$. We could not determine specific IgE to Swiss chard because the material is not commercially available.

Spirometry revealed normal values, with a forced vital capacity (FVC) of $2.71 \mathrm{~L}$, a forced expiratory flow in the first second $\left(\mathrm{FEV}_{1}\right)$ of $2.37 \mathrm{~L}$, and an $\mathrm{FEV}_{1} / \mathrm{FVC}$ ratio of $87 \%$. The bronchodilator result was negative.
At baseline, the methacholine challenge test was negative, the fraction of exhaled nitric oxide (FeNO) was $30.8 \mathrm{ppb}$, and induced sputum (analyzed by flow cytometry) showed an eosinophil count of $0.31 \%$.

A specific inhalation challenge was performed after obtaining signed authorization from the patient. This test was carried out in a room measuring $7 \mathrm{~m}^{3}$, where the patient handled raw Swiss Chard, as she typically did at home, for a total of 65 minutes in periods of 5, 20, and 40 minutes. This challenge did not bring about any changes in $\mathrm{FEV}_{1}$ over a 24hour period. $\mathrm{FEV}_{1}$ and peak expiratory flow were monitored with a computerized asthma monitor (Amos, Jaeger) for 1 day every hour except when the patient was sleeping.

The bronchial challenge with methacholine was performed 24 hours after the specific inhalation challenge and showed a positive result (provocation concentration that caused a $20 \%$ decrease in $\mathrm{FEV}_{1}$ of $0.74 \mathrm{mg} / \mathrm{mL}$. No changes in FeNO were observed and the induced sputum showed an increase in eosinophils $(2.21 \%)$.

Proteins from raw and cooked Swiss chard were extracted by magnetic stirring (overnight at $4^{\circ} \mathrm{C}$ ) in phosphate-buffered saline $(\mathrm{pH} 8)$ at $3 \% \mathrm{wt} / \mathrm{vol}$. Extracts were clarified by centrifugation $\left(10000 \mathrm{rpm}\right.$ for 60 minutes at $\left.4^{\circ} \mathrm{C}\right)$ and dialyzed against distilled water before being filtered and freeze-dried. Protein concentration was estimated using the Bradford assay [3]. Protein profiles of raw and cooked Swiss chard were analyzed by SDS-PAGE under reducing conditions. Proteins bands $(6-200 \mathrm{kDa})$ were detected in both extracts using colloidal blue Coomassie (Sigma-Aldrich).

Immunodetection of proteins bound to specific $\operatorname{IgE}$ contained in patient serum was performed following the protocol established by Gamez et al [4]. Specific IgE-binding bands with an apparent molecular weight of $30 \mathrm{kDa}$ were observed in the raw Swiss-chard extract (Figure). In the case

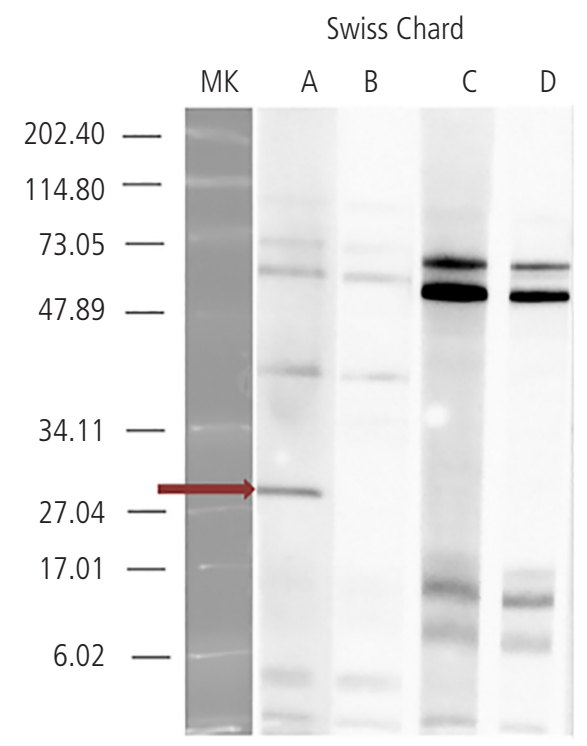

Figure. IgE immunoblot with raw Swiss chard (Lane A, patient's serum; Lane B, negative control) and cooked Swiss chard (Lane C, patient's serum; Lane $\mathrm{D}$, negative control). MK indicates molecular markers ( $\mathrm{kDa}$ ). 
of cooked Swiss-chard extract, specific IgE protein recognition was absent.

The immunoreactive protein was excised from colloidal blue Coomassie-stained gel and digested with trypsin. The resulting peptide mixture was analyzed by Matrix-Assisted Laser Desorption/Ionization Time-of-Flight Mass Spectrometry (MALDI-TOF MS). Protein identification by MALDI-TOF MS was performed as previously described [5]. One novel allergen was identified as a chloroplast chlorophyll a/b binding protein with a molecular weight of $28 \mathrm{kDa}$ (Mowse score, 262; $P<.05$ ). This same protein had been previously identified as a celery allergen called Api $g$ 3. Alignment of the 2 protein sequences revealed a $37 \%$ identity. This lower identity is likely due to the phylogenetic distance between the 2 vegetables.

Due to the similarity described with protein celery, the patient was questioned again about any symptoms displayed with other vegetables, and she reported no reactions of any type on eating or handling celery. However, a prick-prick test with celery was positive. We performed SDS-PAGE using a similar procedure to that described for Swiss chard in a previous paragraph. In this test, some protein bands between $6 \mathrm{kDa}$ and $200 \mathrm{kDa}$ were observed, although immunoblotting with this extract and the patient serum did not reveal any specific IgE-binding bands.

Cases of asthma due to Swiss chard have been described in which certain proteins were identified by immunoblotting. For instance, González-Mancebo et al [6] described a band corresponding to a peptide of $42 \mathrm{KDa}$ and Valbuena et al [7] described several bands with a molecular weight of $16,33,45,70,80$, and $92 \mathrm{kD}$. Neither of the groups, however, sequenced the peptides found. There has also been a report of a case of rhinoconjunctivitis and asthma caused by the inhalation of vapor from boiling Swiss chard in which cross-reactivity with grass pollen was detected by radioallergosorbent inhibition [8]. Our patient was sensitized to certain pollens, but she only exhibited symptoms when handling Swiss chard.

In summary, we have reported the case of a patient with allergy to raw Swiss chard in which an IgE mechanism was demonstrated. Asthma due to the handling of raw Swiss chard is suspected. To our knowledge, this is the first report to identify a new allergen in raw Swiss-chard extract. This allergen is a chloroplast chlorophyll $\mathrm{a} / \mathrm{b}$ binding protein.

\section{Funding}

The authors declare that no funding was received for the present study.

\section{Conflicts of Interest}

The authors declare that they have no conflicts of interest.

\section{References}

1. Ramirez D., Bahna L. Food hypersensitivity by inhalation. Clin Mol Allergy. 2009;7:4.

2. Quirce $S$, Madero MF, Fernández-Nieto $M$, Jiménez $A$, Sastre J. Occupational asthma due to the inhalation of cauliflower and cabbage vapors. Allergy. 2005 Jul; 60(7):969-70.
3. Bradford MM. A rapid and sensitive method for the quantitation of microgram quantities of protein utilizing the principle of protein-dye binding. Anal Biochem. 1976;72:24854.

4. Gamez C., Marchán E, Miguel L, Sanz V, del Pozo V. Goji berry: A potential new player in latex-food syndrome. Ann Allergy Asthma Immunol. 2013;Mar;110(3):206-7.

5. Luengo O, Mollá R, Gámez C, Cardona V, López E, Sastre B, Waisel Y, Belmonte J, Cadahia A, Lahoz C, del Pozo $\mathrm{V}$. Allergenicity and cross-reactivity of Senecio pollen: identification of novel allergens using the immunoproteomics approach. Clin Exp Allergy. 2008;38:1048-60.

6. González-Mancebo E, Alfaya T, Pulido Z, León F, Cuevas M, de la Hoz B. Swiss chard-induced asthma. Allergy. 2000 May; 55(5):511-2.

7. Valbuena T, Barranco P, Pascual C, López-Serrano MC, Quirce S. Late asthmatic reaction induced by exposure to raw Swiss chard. J Investig Allergol Clin Immunol. 2010;20(3):268-9.

8. De la Hoz B, Fernandez-Rivas M, Quirce S, Cuevas M, Fraj J, Dávila I, Igea JM, Losada E. Swiss chard hypersensitivity: clinical and immunologic study. Ann Allergy. 1991;Nov;67(5):487-92.

Manuscript received July 15, 2016; accepted for publication, October 27, 2016

Pamela Jara Gutiérrez

Av. Reyes Católicos, 2 28040 Madrid, Spain E-mail: Pamela.jaragutierrez@gmail.com 


\section{Quality Indicators of Asthma Care Derived From the Spanish Guidelines for Asthma Management (GEMA 4.0): A Multidisciplinary Team Report}

Quirce $\mathrm{S}^{1}$, Delgado $\mathrm{J}^{2}$, Entrenas $\mathrm{LM}^{3}$, Grande $\mathrm{M}^{4}$, Llorente $\mathrm{C}^{4}$, López Viña $\mathrm{A}^{5}$, Martínez Moragón $\mathrm{E}^{6}$, Mascarós $\mathrm{E}^{7}$, Molina $\mathrm{J}^{8}$, Olaguibel $\mathrm{JM}^{9}$, Pérez de Llano $\mathrm{LA}^{10}$, Perpiñá Tordera $\mathrm{M}^{11}$, Quintano JA ${ }^{12}$, Rodríguez $\mathrm{M}^{13}$, Román-Rodriguez $\mathrm{M}^{14}$, Sastre $\mathrm{J}^{15}$, Trigueros $\mathrm{JA}^{16}$, Valero $\mathrm{AL}^{17}$, Zoni $\mathrm{AC}^{18}$, Plaza $\mathrm{V}^{19}$ on behalf of the ASMAFORUM II Group*

*ASMAFORUM II Group: Carlos Almonacid Sánchez, Francisco Javier Álvarez Gutiérrez, María José Álvarez Puebla, Pedro Baños Hidalgo, María Pilar Barranco Sanz, Francisco Javier Callejas González, José Paulino Castañedo Fuentes, Pilar Cebollero Rivas, Carolina Victoria Cisneros Serrano, María Climent Gregori, Carlos Colás Sanz, Juan Manuel Díez Piña, Javier Dominguez Ortega, Luis Fernández Moya, Cayo García Polo, Patricia García Sidro, Ana Paulina Gómez-Bastero Fernández, José Tomás Gómez Sáenz, Elisa Gómez Torrijos, Francis Javier González Barcala, María Teresa Lambán Sánchez, María José Linares Serrano, Juan Marco Such, Nuria Marina Malganda, Juan Antonio Martínez Carbonell, Carlos Martinez Rivera, Victor Manuel Matheu Delgado, Carlos Melero Moreno, María Mar Mosteiro Añón, Karlos Naberán Toña, Concepción Navarro Hernández, Alicia Padilla Galo, Abel Parra Pallares Sanmartín, Antonio Pascual Arrondo, María José Pérez Miravalles, Ignacio Javier Pinedo Camo, Celia María Ramírez Sierra, María Teresa Romero Prieto, Auxiliadora Romero Falcón, Pedro José Sabadell Palacios, Carles Sánchez García Nieto, José Silvia Serrano Pariente, Agustín Sojo González, Andrea Trisán Alonso, José María Vega Chicote, David Yabar Bedoya, José Manuel Zubeldia Ortuño.

${ }^{1}$ Servicio de Alergología, Instituto de Investigación Hospital Universitario La Paz (IdiPAZ), Madrid, Spain

${ }^{2}$ Unidad de Gestión Clínica de Alergología, Hospital Virgen Macarena, Sevilla, Spain

${ }^{3}$ Unidad de Gestión Clínica de Neumología, Hospital Universitario Reina Sofia, Córdoba, Spain

${ }^{4}$ Servicio de Medicina Preventiva y Gestión de Calidad, Hospital General Universitario Gregorio Marañón, SERMAS, Madrid, Spain ${ }^{5}$ Servicio de Neumología, Hospital Universitario Puerta de Hierro, Majadahonda, Madrid, Spain

${ }^{6}$ Servicio de Neumología, Hospital Universitario Dr. Peset, Valencia, Spain

${ }^{7}$ Medicina de Atención Primaria, Centro de Salud Fuente de San Luis, Valencia, Spain; Departamento de Salud, Hospital Dr. Peset, Valencia, Spain

${ }^{8}$ Medicina de Atención Primaria, EAP Francia, Fuenlabrada, Madrid, Spain

${ }^{9}$ Servicio de Alergología, Complejo Hospitalario de Navarra, Pamplona, Spain

${ }^{10}$ Servicio de Neumología, Hospital Universitario Lucus Agusti,

Lugo, Spain

${ }^{11}$ Servicio de Neumología, Hospital Universitario Politécnico La $\mathrm{Fe}$, Valencia, Spain

${ }^{12}$ Medicina de Atención Primaria, Lucena, Córdoba, Spain

${ }^{13}$ Servicio de Alergología, Hospital Príncipe de Asturias, Alcalá de Henares, Madrid, Spain
${ }^{14}$ Medicina de Atención Primaria, Centro de Salud Son Pisá, Instituto de Investigación de Palma de Mallorca (IdisPa), Palma de Mallorca, Spain

${ }^{15}$ Servicio de Alergología, Fundación Jiménez Díaz, CIBER de Enfermedades Respiratorias (CIBERES), Instituto de Salud Carlos III, Madrid, Spain; Universidad Autónoma de Madrid, Madrid, Spain

${ }^{16}$ Medicina de Atención Primaria, Centro de Salud Menasalbas, Toledo, Spain

${ }^{17}$ Servicio de Neumología, Intitut Clinic Respiratori, Hospital Clinic, Institut d'Investigacions Biomédiques August Pi i Sunyer (IDIBAPS), Barcelona, Spain; Centro de Investigaciones Biomédicas en Red de Enfermedades Respiratorias (CIBERES), Spain

${ }^{18}$ Área de Epidemiología, Subdirección de Promoción y Prevención de la Salud, Consejería de Salud de la Comunidad de Madrid, Madrid, Spain

${ }^{19}$ Departmento of Medicina Respiratoria, Hospital de la Santa Creu i Sant Pau. Institut d'Investigació Biomédica Sant Pau (IIB Sant Pau), Universitat Autònoma de Barcelona, Departmento de Medicina, Barcelona, Spain

J Investig Allergol Clin Immunol 2017; Vol. 27(1): 69-73 doi: 10.18176/jiaci.0121

Key words: Asthma. Indicator. Diagnosis. Monitoring. Treatment.

Palabras clave: Asma. Indicador. Diagnóstico. Monitorización. Tratamiento.

Despite attempts made to improve asthma management through the development and implementation of clinical practice guidelines, the routine clinical care of patients with asthma is frequently marked by inefficiencies that contribute significantly to the cost of care. In addition, there are no validated standards or indicators that can help to ensure the correct application and implementation of these guidelines. In this study, we critically appraised and optimized the various diagnostic, therapeutic, and care plan options for patients with asthma. The goal of this project was to establish parameters for improving the care of patients with asthma through the development and validation of quality standards and indicators for asthma management. Although standards and indicators can be established from recommendations, protocols, consensus, and clinical practice guidelines, this project was based exclusively on the recommendations of the Spanish Guidelines for Asthma Management (GEMA 4.0, Guía Española para el Manejo del Asma) [1].

A panel of 65 experts in asthma care participated in the Asmaforum II project, developed by a multidisciplinary working group created to develop scientific projects and offer solutions for the management of asthma. To coordinate this group, a scientific committee was established to manage the project and regularly consult the rest of the members. Seventeen experts ( 2 coordinators, 6 allergists, 6 pulmonologists, and 2 primary care physicians) formed the scientific committee. The project consisted of 5 phases: 1) identification and organization 
of the recommendations contained in the GEMA, 2) selection and review of standards, 3) expert consultation for approving standards, 4) development of quality of care indicators, and 5) prioritization of indicators.

Eighty-two recommendations from the GEMA were identified and grouped according to the following topics: diagnosis $(n=26)$, nonpharmacological treatment $(n=14)$, pharmacological treatment $(n=34)$, and monitoring $(n=8)$. The scientific committee then filtered these recommendations according to their relevance and feasibility in terms of addressing minimum quality of care standards in patients with asthma. They selected $43(52 \%)$ of the 82 recommendations originally identified. These recommendations were presented to the panel of experts, who issued a quantitative assessment based on their relevance, and discussed the most controversial points. Using these assessments and expert opinions, the scientific committee created a shortlist of 35 recommendations.

In a subsequent phase, several of these 35 recommendations were merged or eliminated for not being specific enough to establish an indicator. An expert technical team in healthcare quality indicators developed 20 records using the remaining recommendations (Table). Finally, with the aim of identifying the most significant indicators, a final prioritization was made based on the combination of 2 concepts: the power or effectiveness of the indicator for establishing asthma quality of care and the possibility of applying the indicator to data from common healthcare databases. After this initial prioritization, the top 2 indicators for each scenario were labeled as priority indicators (Table).

The expert group agreed that a diagnosis based on objective evidence is crucial. Spirometry and the bronchodilator test are the most frequently used tests. However, the group also discussed whether fractional exhaled nitric oxide (FeNO) measurements were necessary. Some considered that they were neither necessary nor decisive while others expressed doubts. Studies of allergic sensitization in patients with suspected allergic asthma were also considered a priority. Skin prick testing was determined to be the method of choice due to its high sensitivity, low cost, and immediacy. Other tests such as specific IgE measurement have the same meaning as skin prick tests, but are less sensitive and more expensive [2].

Regarding nonpharmacological treatment options, smoking cessation must be considered a priority in patients with asthma. Asthma patients who smoke have more severe symptoms, worse response to treatment with glucocorticoids, and more rapid loss of lung function than nonsmokers [3]. Regular review of medical charts is also recommended to check the routine implementation of basic interventions for smoking cessation. In addition, structured patient education is one of the most significant indicators of the quality of health care for asthma and must be recognized as a priority because simple information campaigns have not proven to be effective. The most appropriate way to build this indicator is to define a package of concrete and timely basic interventions, and ask if they have been accomplished. Likewise, this indicator may be used as a process indicator in order to simplify measurement and avoid the bias of subjectivity associated with the investigation of the behavior of health professionals $[4,5]$.

The pharmacological treatments of choice for persistent asthma include daily inhaled glucocorticoids as a priority, as these are considered the most effective treatment for both symptom control and prevention of exacerbations [6]. The use of alternative treatments, such as leukotriene receptor antagonists, is adequate, but it should be justified in the clinical documentation. Pharmacological treatment of asthma in pregnant women was the second priority indicator selected. For this group of patients the recommendation is to use standard asthma treatments, such as $\beta_{2}$-adrenergic agonists and inhaled corticosteroids. Although all drugs used to treat asthma can cross the placenta, few have an impact on the fetus. In addition, poorly controlled maternal asthma carries a higher risk to the fetus than the possible adverse effects of the drugs used in the routine treatment of asthma [7].

A final priority was considered to be the periodic monitoring of both exacerbations and day-to-day asthma control. These assessments should be performed periodically in order to check response. In addition, treatment should be adjusted to achieve and maintain asthma control. Parameters to monitor should include, at least, a specific and complete medical history, a detailed physical examination, and a forced spirometry test.

These recommendations and indicators should help to improve the inefficiencies observed in the management of patients with asthma. Although 2 recommendations were prioritized as the most relevant in each group, the other recommendations should also be taken into account as they also reflect many of the current weaknesses that could be improved in asthma care plans.

\section{Acknowledgments}

The Asmaforum II scientific committee would like to thank all the members of the expert group for their work, Dr Fernando Sánchez Barbero for preparing this manuscript, and the Strategic Research in Healthcare Unit from Luzán 5 (Madrid) for assisting with the design and coordination of the project.

\section{Funding}

This research was financially supported by BoehringerIngelheim.

\section{Conflicts of Interest}

The following authors have conflicts of interests. The other authors declare that they do not have any conflicts of interest that may inappropriately influence this work.

Santiago Quirce has been on advisory boards for and has received speaker's honoraria from AstraZeneca, GlaxoSmithKline, MSD, Novartis, Almirall, Chiesi, Boehringer-Ingelheim, and Pfizer.

Julio Delgado has been on advisory boards for BoehringerIngelheim and Teva and has received speaker's honoraria from AstraZeneca, Chiesi, GlaxoSmithKline, MSD, Novartis, Mundipharma, and Pfizer.

Luis Manuel Entrenas has received honoraria in the last 3 years for speaking at sponsored meetings from Alter, Astra-Zeneca, Boehringer-Ingelheim, Chiesi, Esteve, Ferrer, GlaxoSmithKline, Menarini, MSD, Mundipharma, Novartis, Pfizer Takeda-Nycomed, and Teva; consultancy fees from 


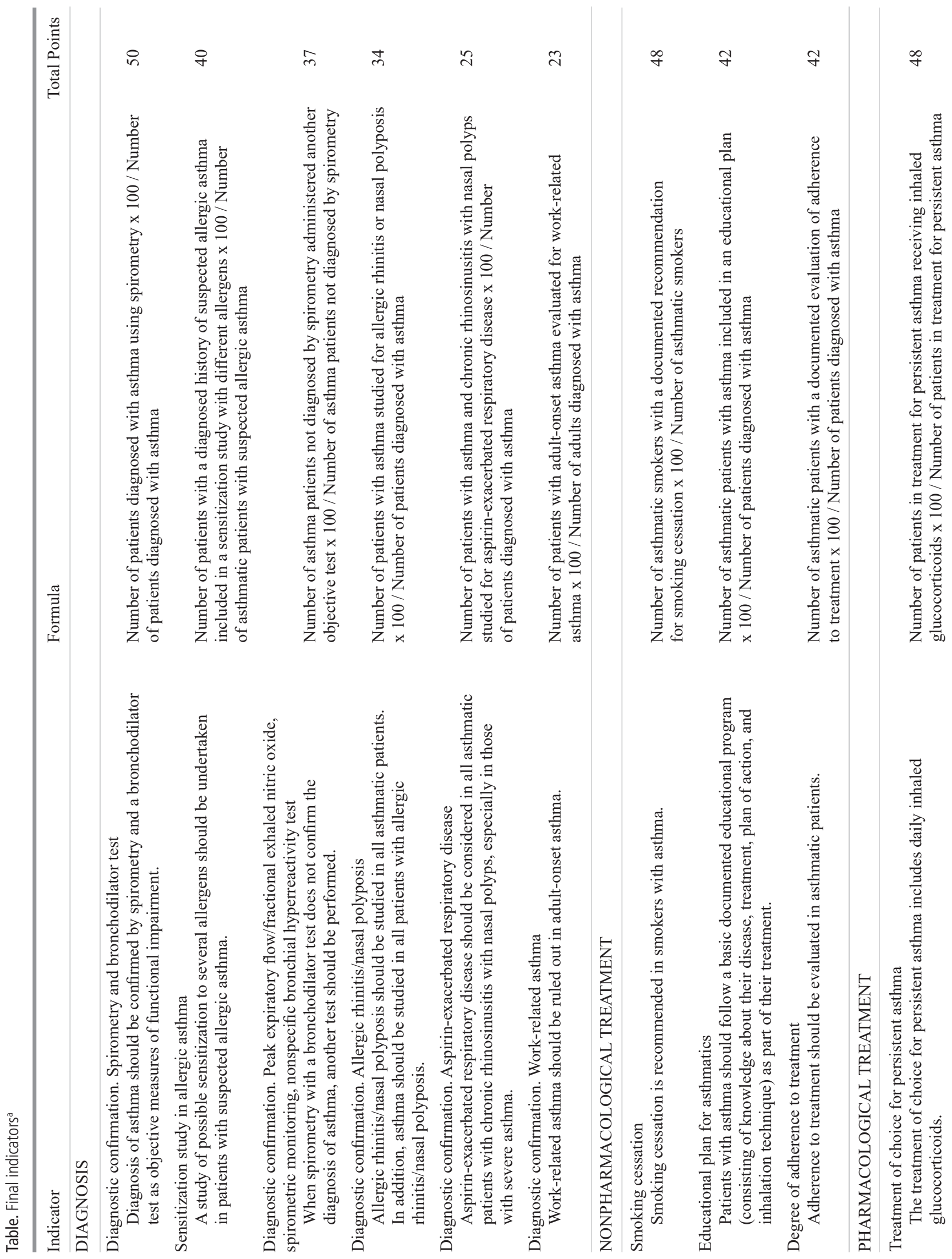


F

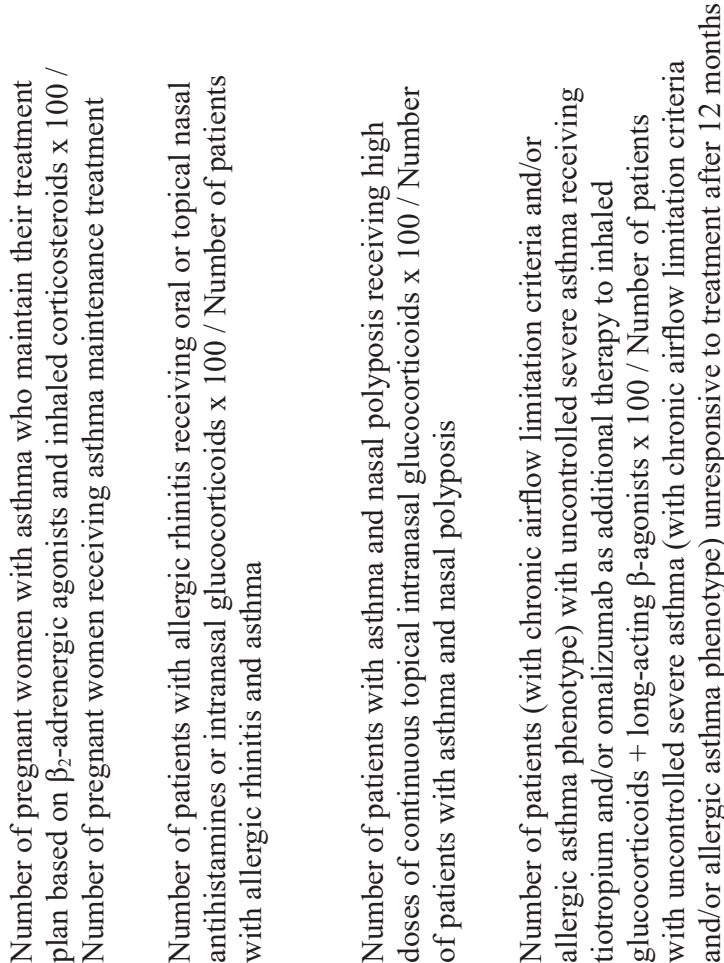

\%

考 㐫

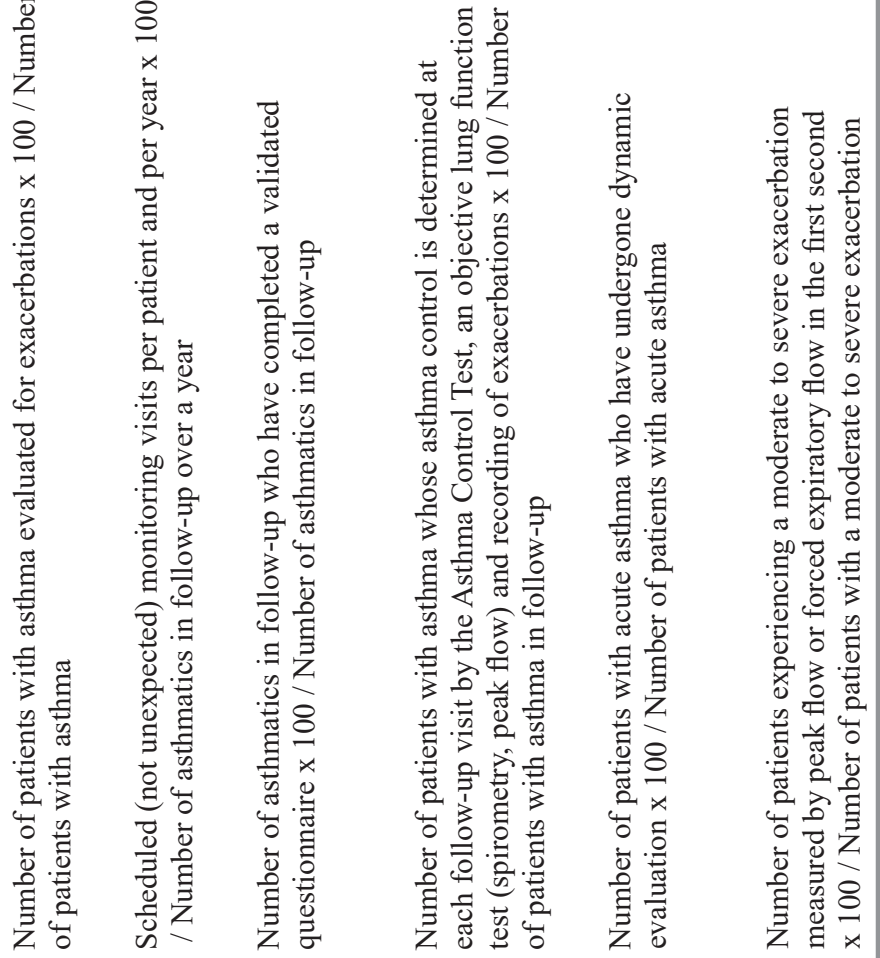

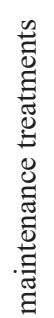

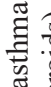

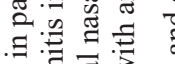

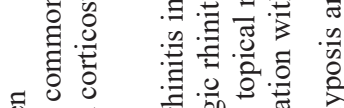

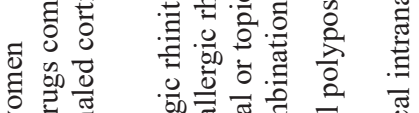

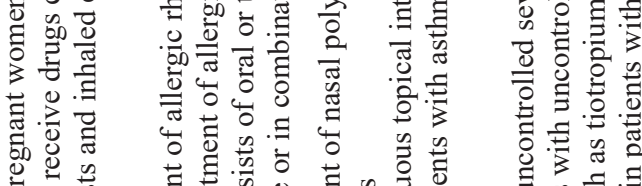

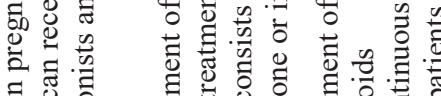

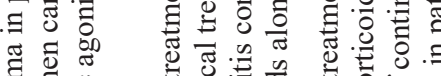

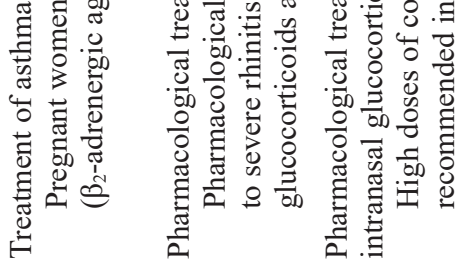

鹿

范

要

要贯

늠

㥼

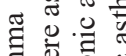

矛总

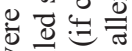

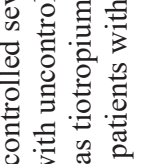

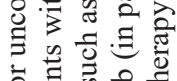

记

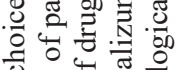

늠

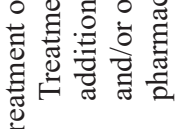

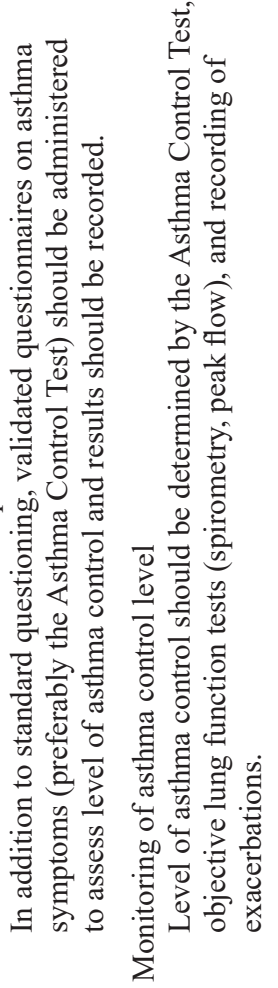

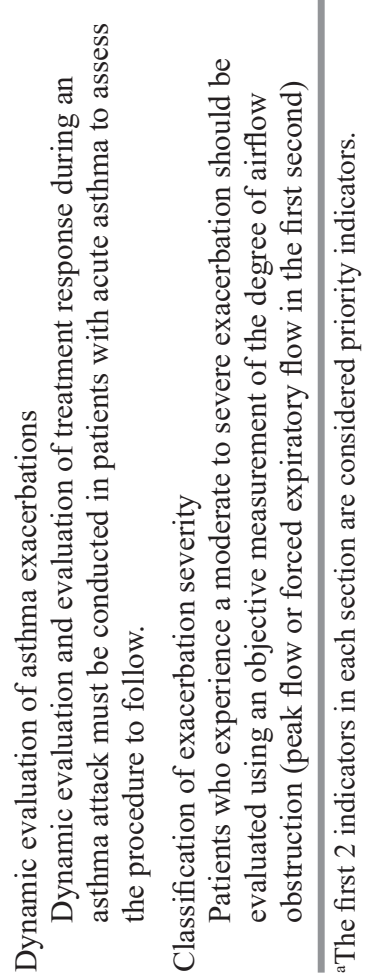


Chiesi, Mundipharma, and Novartis; and funding/grant support for research projects from Novartis, Roche, Sanofi, and Teva.

Antolín López Viña has been on advisory boards for and received speaker's honoraria from Teva, GlaxoSmithKline, Novartis, Chiesi, Boehringer-Ingelheim, and Pfizer in the last 3 years.

Eva Martínez Moragón has been on advisory boards for and received speaker's honoraria from Teva, AstraZeneca, Novartis, Mundipharma, Chiesi, and Boehringer-Ingelheim.

Enrique Mascarós has received honoraria for speaking at sponsored meetings or participating on advisory boards from AstraZeneca, Boehringer-Ingelheim, Chiesi, GlaxoSmithKline, Gebro, Mundipharma, Rovi, Pfizer, and Teva.

Jesús Molina has collaborated as a speaker and/or consultant and/or investigator for initiatives and projects sponsored by Astra-Zeneca, Boehringer-Ingelheim, Esteve, GlaxoSmithKline, MSD, Menarini, Mundifarma, Novartis, Pfizer, Roche, Rovi, Sandoz, Takeda, and Teva.

José María Olaguibel has been on advisory boards for and has received speaker's honoraria from ALK, AstraZeneca, GlaxoSmithKline, Mundipharma, Chiesi, and BoehringerIngelheim.

Luis Alejandro Pérez de Llano has been on advisory boards for and has received speaker's honoraria from Novartis, Teva, Sandoz, AstraZeneca, Pfizer, Zambon, Mundipharma, Chiesi, and Boehringer-Ingelheim

Miguel Perpiñá Tordera has been on advisory boards for and has received speaker's honoraria from GSK, Chiessi, and Boehringer-Ingelheim.

José Antonio Quintano has received honoraria for speaking at sponsored meetings from AstraZeneca, BoehringerIngelheim, Esteve, Gebro, GlaxoSmithKline, Menarini, Mundipharma, Pfizer, Rovi, and TEVA in the last 3 years.

Mercedes Rodríguez has been on advisory boards for Boehringer-Ingelheim and Novartis and has received speaker's honoraria from Teva, GSK, Novartis, Mundipharma, and AstraZeneca.

Miguel Román-Rodríguez has received honoraria for speaking at sponsored meetings or participating on advisory boards from AstraZeneca, Boehringer-Ingelheim, Chiesi, GlaxoSmithKline, Gebro, Mundipharma, Rovi, Pfizer, and Teva.

Joaquin Sastre has served as a consultant to Thermo Fisher Scientific, Merck, FaesFarma, Novartis, Roche, Sanofi, Genetech, and GlaxoSmithKline; has been paid lecture fees by Novartis, GlaxoSmithKline, Stallergenes, FaesFarma, and $\mathrm{UCB}$; and has received grant support from Thermo Fisher Scientific, GlaxoSmithKline, and ALK-Abelló.

Juan Antonio Trigueros has received honoraria for speaking at sponsored meetings from Boehringer-Ingelheim, Chiesi, Pfizer, and Teva in the last 3 years.

Antonio Luis Valero has been on advisory boards for and has received speaker's honoraria from Novartis, Sanofi, GlaxoSmithKline, Chiesi, Boehringer-Ingelheim, FaesFarma, Meda, Orion Pharma, Stallergenes, Leti, and Uriach.

Vicente Plaza has received honoraria for speaking at sponsored meetings from AstraZeneca, Boehringer-Ingelheim, Chiesi, GlaxoSmithKline, Merck, Mundipharma, and Pfizer in the last 3 years, and has received consultancy fees from
Mundipharma, Orion, and Teva. In addition, he has received travel grants from Boehringer-Ingelheim and Chiesi and funding/grant support for research projects from a variety of government agencies and not-for-profit foundations, as well as from Chiesi and Menarini.

\section{References}

1. Plaza Moral V; Comité Ejecutivo de GEMA. GEMA (4.0). Spanish guideline on the management of asthma. J Investig Allergol Clin Immunol. 2016;26:1-92.

2. Bousquet J, Heinzerling L, Bachert C, Papadopoulos NG, Bousquet PJ, Burney PG, Canonica GW, Carlsen KH, Cox L, Haahtela T, Lodrup Carlsen KC, Price D, Samolinski B, Simons FE, Wickman M, Annesi-Maesano I, Baena-Cagnani CE, Bergmann KC, Bindslev-Jensen C, Casale TB, Chiriac A, Cruz AA, Dubakiene R, Durham SR, Fokkens WJ, Gerth-van-Wijk R, Kalayci O, Kowalski ML, Mari A, Mullol J, Nazamova-Baranova L, O'Hehir RE, Ohta K, Panzner P, Passalacqua G, Ring J, Rogala B, Romano A, Ryan D, Schmid-Grendelmeier P, Todo-Bom A, Valenta R, Woehrl S, Yusuf OM, Zuberbier T, Demoly P. Allergic Rhinitis and its Impact on Asthma. Practical guide to skin prick tests in allergy to aeroallergens. Allergy. 2012;67:18-24.

3. Lazarus SC, Chinchilli VM, Rollings NJ, Boushey HA, Cherniack $R$, Craig TJ, Deykin A, DiMango E, Fish JE, Ford JG, Israel E, Kiley J, Kraft M, Lemanske RF Jr, Leone FT, Martin RJ, Pesola GR, Peters SP, Sorkness CA, Szefler SJ, Wechsler ME, Fahy JV. Smoking affects response to inhaled corticosteroids or leukotriene receptor antagonists in asthma. Am J Respir Crit Care Med. 2007:175:783-90.

4. Gibson PG, Powell H, Coughlan J, Wilson AJ, Abramson M, Haywood P, Bauman A, Hensley MJ, Walters EH. Selfmanagement education and regular practitioner review for adults with asthma. Cochrane Database Syst Rev. 2003:CD001117.

5. Powell H, Gibson PG. Options for self-management education for adults with asthma. Cochrane Database Syst Rev. 2003:CD004107.

6. Reddel HK, Belousova EG, Marks GB, Jenkins CR. Does continuous use of inhaled corticosteroids improve outcomes in mild asthma? A double-blind randomised controlled trial. Prim Care Respir J. 2008:17:39-45.

7. Lim A, Stewart K, Konig K, George J. Systematic review of the safety of regular preventive asthma medications during pregnancy. Ann Pharmacother. 2011;45:931-45.

Manuscript received October 6 2016; accepted for publication, November 3, 2016.

Santiago Quirce

Servicio de Alergología Hospital Universitario La Paz

Paseo de la Castellana, 261 - 28046 Madrid, Spain E-mail: squirce@gmail.com 


\section{Chronic Urticaria After Implantation of a Mitral Annuloplasty Ring in a Nickel-Allergic Patient}

Díaz Palacios MA ${ }^{1}$, López-Salgueiro $\mathrm{R}^{1}$, Mencía Sanchez $\mathrm{G}^{2}$, Martínez Romero $\mathrm{A}^{3}$, Morales-Rubio $\mathrm{A}^{4}$, Hernández Fernández de Rojas $\mathrm{D}^{1}$

${ }^{I}$ Department of Allergy, IIS Hospital La Fe, Valencia, Spain

${ }^{2}$ Department of Allergy, Hospital de La Plana, Castellón, Spain

${ }^{3}$ Research Institute "Príncipe Felipe”, Valencia, Spain

${ }^{4}$ Analytical Chemistry Department, Facultat de Química, Universitat de València, Valencia, Spain

J Investig Allergol Clin Immunol 2017; Vol. 27(1): 74-75 doi: $10.18176 /$ jiaci.0125

Key words: Chronic urticaria. Nickel allergy. Annuloplasty ring.

Palabras clave: Urticaria crónica. Alergia a níquel. Anillo de anuloplastia.

Endovascular devices containing nickel can elicit systemic allergic dermatitis [1-3]. It has also been reported that allergy to nickel can occasionally provoke urticaria [4] and anaphylaxis [5]. Contact hypersensitivity has been implicated in the complications of prosthetic valve replacement and restenosis of cardiac stents and other endovascular devices [6]. We report a case of severe chronic urticaria after mitral annuloplasty with a ring implant made of Elgiloy (an alloy consisting of cobalt $40 \%$, chromium $20 \%$, nickel $15 \%$, molybdenum $7 \%$, and manganese $2 \%$ ) in a patient with contact hypersensitivity to nickel.

A 57-year-old male presented with severe urticaria and angioedema 2 weeks after implantation of a mitral valve with a Physio type annuloplasty ring (Carpentier Edwards). Urticarial lesions persisted despite treatment with high doses of antihistamines and oral corticosteroids and discontinuation of cardiac medications (acenocoumarol, acetylsalicylic acid, amiodarone, bisoprolol, and omeprazole) and antiplatelet treatment (Figure). The patient had a history of dermatitis after contact with metals, although he had not been specifically assessed before surgery. Patch tests were carried out with the baseline series of the Spanish Contact Dermatitis and Skin Allergy Research Group (GEIDAC) and a metal series (BialAristegui). A positive result was observed for nickel $(+++)$ on D2 and D4. The result of patch testing with Elgiloy was negative. Food allergy was ruled out, and serology testing for viruses was negative. Total $\mathrm{IgE}$ was $180 \mathrm{kU} / \mathrm{L}$ (reference range, $0-100 \mathrm{kU} / \mathrm{L}$ ) and serum tryptase was $3.4 \mu \mathrm{g} / \mathrm{L}$ (reference range, $<11.4 \mu \mathrm{g} / \mathrm{L}$ ). An echocardiogram confirmed the normal functioning of the annuloplasty ring. The Physio type ring safety information showed a total nickel ion release of $<2$ ppb after 60-day immersion in a physiological solution using inductively coupled plasma, with no evidence of Elgiloy band corrosion. Nickel was not detected in the patient's serum by inductively coupled plasma optical emission spectrometry, with a detection threshold of $20 \mathrm{ppb}(\mathrm{ng} / \mathrm{mL})$, or with electrothermal atomic absorption spectroscopy, with a detection threshold of $3 \mathrm{ppb}(\mathrm{ng} / \mathrm{mL})$.

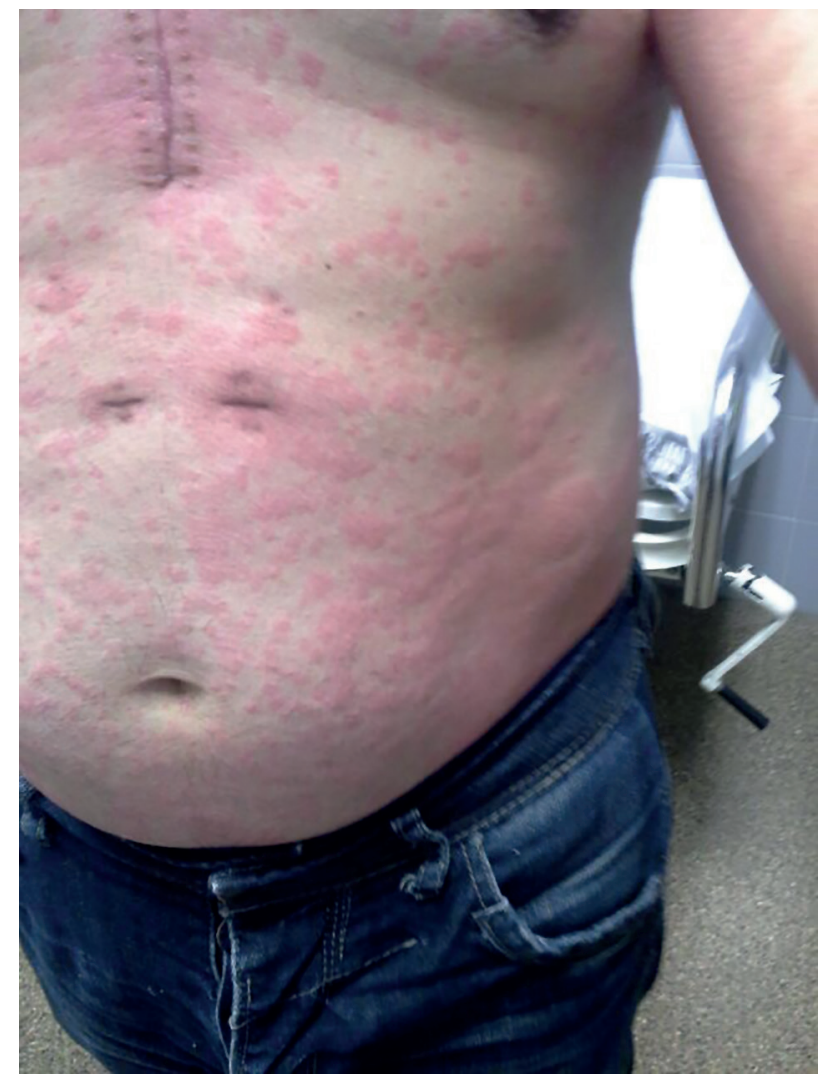

Figure. Urticaria lesions 2 weeks after valve implantation.

Treatment with anti-IgE was rejected by the patient, who requested that the implant be removed. One year after the onset of symptoms, the ring was removed. During the early postoperative period, he experienced an exacerbation of urticaria that required temporary intensification of therapy with antihistamines and corticosteroids. Since then (24 months), he has remained asymptomatic without medication.

In order to study the influence of nickel exposure on cell activation we performed basophil and lymphocyte activation tests using flow cytometry-based assays. The results are considered positive when activation is $>5 \%$ or the stimulation index is $>2$. Basophil activation after exposure to 2 dilutions $(1 / 100,1 / 10)$ of nickel chloride $0.01 \mathrm{M}$ and cobalt chloride $0.01 \mathrm{M}$ was measured based on the expression of CD63 using a commercial kit (BASOTEST). Activation of mononuclear cells after incubation with 5 different concentrations of nickel chloride $(100,200,500,750$, and $1000 \mu \mathrm{g} / \mathrm{mL})$ and 4 different concentrations of cobalt chloride $(0.1,0.25,0.5$, and $1 \mathrm{mM})$ was evaluated by observing changes in CD69 expression. Both tests, which were performed after resolution of the episode, yielded negative results.

In the case we report, urticaria was not initially attributable to nickel sensitization, although after some months of continuous and disabling urticaria, the valve was removed and symptoms resolved completely. This outcome suggests that urticaria was induced by the nickel in the annuloplasty ring implant, to which the patient was allergic. However, it was not 
possible to demonstrate release of nickel from the implanted device or accumulation of nickel in serum. Moreover, negative results in the basophil activation test suggest that an IgE-mediated mechanism is unlikely. Immunological studies performed in nickel-sensitized patients with respiratory symptoms, urticaria, and/or angioedema, showed intense lymphocyte proliferation (lymphocyte transformation test stimulation index) and higher IL-4 and IL-10 production than those who had only oral symptoms or systemic dermatitis [5]. In the case reported here, we used an alternative to the lymphocyte transformation test, as expression of CD69 after in vitro stimulation correlates with cell proliferation. However, we failed to demonstrate expression of CD69 by mononuclear cells in the presence of nickel. A limitation of this approach is that neither of the in vitro tests has been clinically validated. There is a clear temporal relationship between the episode of chronic severe urticaria and the implantation of the annuloplasty ring. It seems unlikely that the nickel contained in the annuloplasty ring was responsible for the symptoms of urticaria. Moreover, the metal staples used in the sternotomy (which also contained nickel) were well tolerated by the patient. We failed to find alternative mechanisms to explain the episode of chronic severe urticaria, which resolved after the removal of the annuloplasty ring prosthesis.

\section{Funding}

The authors declare that no funding was received for the present study.

\section{Conflicts of Interest}

The authors declare that they have no conflicts of interest.

\section{References}

1. Giménez-Arnau A, Riambau V, Serra-Baldrich $E$, Camarasa JG. Metal-induced generalized pruriginous dermatitis and endovascular surgery. Contact Dermatitis. 2000;43:35-40.

2. Raison-Peyron N, Guillard O, Khalil Z, Guilhou JJ, Guillot B. Nickel-elicited systemic contact dermatitis from a peripheral intravenous catheter. Contact Dermatitis. 2005;53:222-5.

3. Nosbaum A, Rival-Tringali AL, Barth $X$, Damon $H$, VitalDurand $\mathrm{H}$, Claudy A, Faure M. Nickel-induced systemic allergic dermatitis from a sacral neurostimulator. Contact Dermatitis. 2008:59:319-20.

4. Hession MT, Scheinman PL. The role of contact allergens in chronic idiopathic urticaria. Dermatitis. 2012;23(3):110-6.

5. Büyüköztürk $S$, Gelincik $A$, Ünal $D$, Demirtürk $M$, Çelik DD, Erden S, Çolakoğlu B, Erdem Kuruca S. Oral nickel exposure may induce Type I hypersensitivity reaction in nickel-sensitized subjects. Int Immunopharmacol. 2015;26(1):92-6.

6. Honari G, Ellis SG, Wilkoff BL, Aronica MA, Svensson LG, Taylor JS. Hypersensitivity reactions associated with endovascular devices. Contact Dermatitis. 2008;59:7-22.

Manuscript received September 20, 2016; accepted for publication December 5, 2016.

Miguel Angel Díaz Palacios Department of Allergy IIS Hospital La Fe Valencia, Spain E-mail: diaz_mig@gva.es 